\title{
PEMERIKSAAN TUMBUH KEMBANG BALITA DI TPA TAMBUSAI KABUPATEN KAMPAR
}

\author{
Syukrianti Syahda ${ }^{1}$, Erma Kasumayanti ${ }^{2}$, Endang Mayasari ${ }^{3}$ \\ ${ }^{1,2,3)}$ Program Studi DIV Kebidanan, Fakultas Ilmu Kesehatan, Universitas Pahlawan Tuanku Tambusai \\ e-mail: syukrianti@gmail.com
}

\begin{abstract}
ABSTRAK
Untuk mendapatkan sumber daya manusia yang berkualitas perlu dilakukan pemantapan terhadap tumbuh kembang anak agar tidak terjadi kelainan. Pemantauan tumbuh kembang Balita bertujuan untuk mengobservasi dengan melihat perkembangan normal balita. Kegiatan pengabdian ini dilakukan dengan metode pemeriksaan tumbuh kembang, ceramah dan demonstrasi. Hasil pemeriksaan Balita di TPA Tambusai terkait Tumbuh Kembang diketahui bahwa dari 12 Balita yang diperiksa terdapat 2 Balita (17\%). yang mengalami keterlambatan atau gangguan perkembangan. Sedangkan 10 Balita (83\%)berada pada kategori normal. Terdapat peningkatan sebanyak $75 \%$ pengetahuan dari peserta tentang pemantauan tumbuh kembang Balita di TPA Tambusai. Hasil pelatihan tumbuh kembang balita di TPA Tambusai yaitu $100 \%$ mampu mempraktikkan cara mendeteksi tumbuh kembang. Berdasarkan hasil kegiatan PKM diharapkan kepada pengasuh untuk melakukan stimulasi kepada anak yang tidak normal dan kepada kepala TPA untuk melakukan skrining disetiap tahapan perkembangan anak.
\end{abstract}

Kata kunci: Pemeriksaan Tumbuh kembang Balita, penyuluhan, pelatihan

\section{ABSTRACT}

To get quality human resources, it is necessary to strengthen the child's growth and development to avoid abnormalities. Toddler growth and development aims to observe by looking at the normal development of toddlers. This community service is carried out using the growth and inspection method, lectures and demonstrations. The results of examination of toddlers in Tambusai Landfill related to Growth and Development it is known that of the 12 Toddlers examined there were 2 Toddlers (17\%). who experience delays or developmental disorders. While 10 toddlers $(83 \%)$ are in the normal category. There was a $75 \%$ increase in the knowledge of participants about monitoring the growth and development of toddlers at the Tambusai Landfill. The results of training for toddlers growth and development in TPA Tambusai are 100\% able to practice how to detect growth and development. Based on the results of PKM activities it is expected that caregivers will stimulate abnormal children and the head of the TPA to screen each stage of child development.

Keywords: Toddlers Growth Development, counseling, training

\section{PENDAHULUAN}

Memiliki anak yang sehat, cerdas, berpenampilan menarik (tampan dan cantik), dan berakhak mulia merupakan harapan setiap keluarga. Agar dapat memiliki anak yang diidamkan tersebut maka harus diupayakan sejak seorang calon Bapak atau Ibu memiliki calon pasangan hidup dengan prinsip bibit, bobot, bebet sekarang semakin diabaikan. Untuk mendapatkan anak yang didambakan perlu diperhatikan factor - factor yang mempengaruhi tumbuh kembang anak 
sejak dalam kandungan ibunya dan setelah lahir. Faktor - faktor tersebut adalah faktor genetic /keturunan dan lingkungan bio- fisiko psiko - sosial. Proses tumbuh kembang merupakan hasil interaksi factor - faktor tersebut.

Untuk mendapatkan sumber daya manusia yang berkualitas perlu dilakukan pemantapan terhadap tumbuh kembang anak supaya tidak terjadi kelainan. Ibu merupakan pengasuh utama anak yang dapat mematui pertumbuhan anak Kader Posyandu yang melakukan penimbangan anak dan penyuluhan kesehatan pada ibu setiap bulan, sangat memerlukan pengetahuan tentang deteksi dini kelainan tumbuh kembang anak.

Tumbuh kembang anak yang sudah dimulai sejak bertemunya sperma dan sel telur sampai dewasa itu mempunyai ciri - ciri tersendiri, proses yang kontinyu sejak dari mudugah sampai maturitas /dewasa, yang dipengaruhi oleh factor bawaan dan lingkungan. Ini berarti bawha tumbuh kembang sudah terjadi sejak didalam kandungan dan setelah kelahiran merupakan suatu masa periode tertentu terdapat adanya masa percepatan atau masa perlambatan, serta laju tumbuh kembang yang berlaianan diantara organ - organ. Terdapat 3 periode pertumbuhan cepat adalah pada masa janin, masa bayi $0-1$ tahun dan masa pubertas. Sedangkan pertumbuhan organ - organ tubuh mengikuti 4 pola, yaitu pola umum, limfoid, neural dan reproduksi.

Untuk mengatasi kelainan tumbuh kembang pada anak, ada beberapa hal yang dapat dilakukan pasangan suami istri yang belum mememiliki keturunan dapat melaksanakan berbagai upaya pencegahan, Ibu hamil seyogyanya melakukan pencegahan dan pemeriksaan terpadu, ibu bersalin sebaiknya di tolong paramedis terlatih di tempat pelayanan kesehatan, serta perawatan dan pemeliharaan anak - anak dengan optimal pada fase tumbuh kembang. jika orang tua sudah memiliki anak dengan kelainan tumbuh kembang, tetap ada beberapa upaya penanganan sehingga dapat meminimalkan gangguan pada anak serta mencegah kecacatan yang lebih parah.

Deteksi dini terhadap tumbuh kembang anak perlu dilakukan mulai perkembangan pada kehamilan sampai dilahirkan dan pada masa balita. Berdasarkan survey yang dilakukan di TPA Tambusai menunjukkan bahwa adanya balita yang mengalami gangguan pertumbuhan sebanyak $2 \%$. Oleh karena itu perlu dilakukan pemantauan lebih lanjut terhadap pertumbuhan dan perkembangan Balita.

Pemantauan tumbuh kembang Balita ini bertujuan untuk mengobservasi dengan melihat perkembangan normal, kelainan atau gangguan perkembangan secara dini untuk mencegah masalah kesehatan Balita.

\section{METODE}

Metode yang digunakan dalam pengabdian masyarakat ini adalah dengan melakukan a). Pemeriksaan tumbuh kembang pada balita, yaitu dengan cara mengukur perkembangan balita menggunakan Formulir Deteksi Dini Tumbuh Kembang (Formulir DDTK). b) Penyuluhan tentang tumbuh kembang, yang bertujuan yaitu meningkatkan pemahaman pengasuh terhadap pertumbuhan dan perkembangan anak balita. c) Pelatihan tentang tumbuh kembang, yang bertujuan meningkatkan keterampilan pengasuh dalam memantau pertumbuhan dan perkembangan anak balita.

\section{HASIL DAN PEMBAHASAN}

Hasil pelaksanaan kegiatan PPM secara garis besar dapat dilihat berdasarkan komponen sebagai berikut:

1. Pemeriksaan tumbuh kembang balita

Hasil pemeriksaan Balita di TPA Tambusai terkait Tumbuh Kembang diketahui bahwa dari 12 Balita yang diperiksa terdapat 2 Balita (17\%). yang mengalami keterlambatan atau gangguan perkembangan. Sedangkan 10 Balita (83\%)berada pada kategori normal.

Anak merupakan generasi penerus kehidupan sebuah bangsa, tinggi rendahnya peradaban suatu bangsa ditentukan oleh anak sebagai generasi penerusnya. Masa depan suatu bangsa tergantung pada keberhasilan anak mencapai pertumbuhan dan perkembangan yang optimal. Proses tumbuh kembang anak yang penting yaitu pada 
masa periode balita (usia dibawah 5 tahun) (Adriana, 2011). Berdasarkan penelitian longitudinal mengenai kecerdasan, menunjukkan bahwa kurun waktu 4 tahun pertama usia anak, perkembangan kognitifnya mencapai sekitar 50\%, dalam kurun waktu 8 tahun mencapai $80 \%$, dan mencapai $100 \%$ setelah anak berusia 18 tahun (Departemen Kesehatan RI, 2010, Departemen Kesehatan RI 2012, Departemen Kesehatan RI 2016).

Kegiatan stimulasi dan deteksi dini penyimpangan perlu dilakukan untuk mendeteksi secara dini adanya penyimpangan tumbuh kembang balita termasuk menindaklanjuti setiap keluhan orang tua terhadap tumbuh kembang anak (IDAI, 2015). Apabila ditemukan ada penyimpangan, maka dilakukan intervensi dini penyimpangan tumbuh kembang balita sebagai tindakan koreksi dengan memanfaatkan plastisitas otak anak agar tumbuh kembangnya kembali normal dan penyimpangan tidak semakin berat. Apabila balita perlu dirujuk maka rujukan harus dilakukan sedini mungkin sesuai indikasi. Kegiatan stimulasi dan deteksi dini penyimpangan tumbuh kembang balita yang menyeluruh dan terkoordinasi diselenggarakan dalam bentuk kemitraan antara keluarga (orang tua, pengasuh anak), masyarakat (kader, tokoh masyarakat, organisasi, lembaga swadaya masyarakat), dan tenaga profesional (kesehatan, pendidikan, sosial) (Departemen Kesehatan RI, 2014).

2. Penyuluhan tumbuh kembang balita

Ada peningkatan $75 \%$ pengetahuan dari peserta tentang pemantauan tumbuh kembang Balita di TPA Tambusai sehingga peserta bisa mengetahui gangguan perkembangan Balita yang dititipkan di TPA Tambusai. Penyuluhan ini menggunakan metode ceramah tanya jawab untuk mendukung kemampuan peserta dalam menguasai materi yang disampaikan. Penyuluhan ini dapat meningkatkan pengetahuan pengasuh dalam mendeteksi tumbuh kembang pada anak balita.

3. Pelatihan tumbuh kembang balita

Hasil pelatihan tumbuh kembang balita di TPA Tambusai adalah dari 6 orang peserta yang diundang berdasarkan arahan Kepala TPA (100\%) dapat menghadiri kegiatan pelatihan dan semua peseta mampu mempraktikkan cara mendeteksi tumbuh kembang. Agar tenaga kesehatan, keluarga, pengasuh anak, dan masyarakat (kader) dapat melakukan upaya pembinaan tumbuh kembang anak yang komprehensif, berkualitas dan berkelanjutan sesuai dengan kebutuhan anak, maka dibutuhkan suatu standar pedoman dalam stimulasi dan deteksi dini pertumbuhan dan perkembangan anak, intervensi serta stimulasi dini anak sampai dengan usia 6 tahun (Maritalia, 2009). Pada kegiatan PKM ini, Pengasuh anak dibekali dengan buku pedoman pelaksanaan SDIDTK.

Berdasarkan penelitian yang dilakukan oleh Widaningsih Darajat, dan Dirgahayu (2012) terhadap 35 anak usia 4-24 bulan yang memiliki risiko gangguan tumbuh kembang. Penelitian dilakukan dengan cara melakukan pengukuran deteksi dini tumbuh kembang (DDTK) kemudian ibu diajarkan cara stimulasi DDTK oleh kader. Selanjutnya menganjurkan untuk dipraktikan di rumah kepada anaknya selama satu bulan serta dilakukan kontrak untuk pemeriksaan DDTK satu bulan kemudian. Hasil penelitian ini menunjukkan adanya pengaruh stimulasi deteksi dini tumbuh kembang terhadap penurunan risiko gangguan tumbuh kembang pada sebanyak 23 anak $(65,7 \%)$ dan tetap sebanyak 12 anak $(34,3 \%)$. Sehingga penelitian tersebut menyimpulan SDIDTK efektif dalam meningkatkan perkembangan anak usia 4-24 bulan. 
PKM ini dapat memberikan kontribusi dalam peningkatan pengetahuan dan keterampilan pengasuh di TPA Tambusai, dan intervensi dini tumbuh kembang pada anak balita. Dengan meningkatnya pengetahuan dan keterampilan pengasuh balita dalam melakukan SDIDTK, maka akan meningkatkan kualitas pertumbuhan dan perkembangan anak secara optimal maksimal. Pengasuh juga menginginkan dilanjutkannya kegiatan ini, terutama kegiatan tindak lanjut penemuan dan pelaporan kasus atau penyimpangan tumbuh kembang (cases finding) pada anak di TPA Tambusai dengan mendapatkan pendampingan dari Tim PKM Universitas Pahlawan Tuanku Tambusai. Sehingga hasil temuan ini dapat di follow up dan ditangani secara tepat.

\section{SIMPULAN}

Melalui kegiatan PKM pemantauan tumbuh kembang balita di TPA tambusai diketahui bahwa sebagian besar balita berada pada kategori normal, sebagian besar peserta terdapat peningkatan pengetahuan terkait tumbuh kembang balita, dan sebagian besar peserta mampu mempraktikkan cara melakukan pemantauan tumbuh kembang balita.

\section{SARAN}

Berdasarkan hasil kegiatan PKM diharapkan kepada pengasuh untuk melakukan stimulasi kepada anak yang tidak normal dan kepada kepala TPA untuk melakukan skrining disetiap tahapan perkembangan anak.

\section{UCAPAN TERIMA KASIH}

Kegiatan Pengabdian Kepada Masyarakat berupa penyuluhan dan pelatihan Stimulasi Deteksi dan Intervensi Dini Tumbuh Kembang (SDIDTK) pada Anak Usia 0-5 Tahun di TPA Tambusai ini dapat terlaksana atas fasilitasi Pengabdian Kepada Masyarakat (PKM) yang dibiayai oleh Internal Fakultas Kesehatan Universitas Pahlawan Tuanku Tambusai. Oleh karena itu, tim PKM menyampaikan ucapan terimakasih kepada semua pihak yang telah membantu pelaksanaan kegiatan ini yaitu: Dekan Fakultas Kesehatan Universitas Pahlawan Tuanku Tambusai; Ketua LPPM, Kepala TPA dan Pengasuh Tambusai, dosen-dosen dan mahasiswa Universitas Pahlawan Tuanku Tambusai.

\section{DAFTAR PUSTAKA}

Adriana, D. (2011). Tumbuh kembang dan terapi pada anak. Jakarta: Salemba Medika.

Departemen Kesehatan RI. (2016). Pedoman pelaksanaan stimulasi, deteksi, dan intervensi dini tumbuh kembang anak. Jakarta: Depkes RI.

IDAI. (2016). Deteksi dan stimulasi dini tumbuh kembang dalam 1000 hari pertama (Bahan pelatihan SDIDTK). Jakarta: IDAI.

Jeharsae, R., Sangthong, R., Wichaidit, W., \& Chongsuvivatwong, V. (2013). Growth and development of children aged 1-5 years in low-intensity armed conflict areas in Southern Thailand: A community-based survey. Conflict and Health, 7(8), 1-8.

Lestari, S., Yani, D.I., \& Nurhidayah, I. (2018). Kebutuhan orang tua dengan anak disabilitas. Journal of Nursing Care, 1(1). DOI: https://doi.org/10.24198/jnc.v1i1.15764.

Maritalia, D. (2009). Analisis pelaksanaan program stimulasi, deteksi dan intervensi dini tumbuh kembang (SDIDTK) balita dan anak pra sekolah di Puskesmas Kota Semarang tahun 2009. Tesis. Universitas Diponegoro. Semarang.

Naim, R., Juniarti, N., \& Yamin, A. (2017). Pengaruh edukasi berbasis keluarga terhadap intensi ibu hamil untuk optimalisasi nutrisi pada 1000 hari pertama 
kehidupan. Jurnal Keperawatan Padjadjaran, 5(2). DOI: https://doi.org/10.24198/jkp.v5i2.475.g166.

Needlman, R.D. (2011). Growth and development. Dalam: Behrman, R.E., Kliegman, R.M., \& Jenson, H.B., penyunting. Nelson textbook of pediatrics (edisi ke-19). Philadelphia: WB Saunders Company.

Palasari, D., \& Purnomo, D.I.S.H. (2012). Keterampilan ibu dalam deteksi dini tumbuh kembang terhadap tumbuh kembang bayi. Jurnal Stikes, 5(1).

Kemenkes RI. (2016) Pedoman Pelaksanaan Stimulasi, Deteksi dan Intervensi Dini Tumbuh Kembang.

Soetjiningsih. (2012). Perkembangan anak dan permasalahannya dalam Buku Ajar I Ilmu Perkembangan Anak dan Remaja. Jakarta: Sagung Seto

Sugiyono. (2013). Metode penelitian kuantitatif, kualitatif dan $R \& D$. Bandung: Alfabeta CV.

Suryanto, Purwandari, H., \& Mulyono, W. (2014). dukungan keluarga dan sosial dalam pertumbuhan dan perkembangan personal sosial, bahasa dan motorik pada balita di Kabupaten Banyumas. Jurnal Kesehatan Masyarakat, 10(1), 103-109.

Tanuwidjaya, S. (2012). Konsep umum tumbuh kembang dalam Buku Ajar I Ilmu Perkembangan Anak dan Remaja. Jakarta: Sagung Seto.

Widaningsih, I., Darajat, A.M., dan Dirgahayu, I. (2012). Pengaruh stimulasi deteksi dini tumbuh kembang (DDTK) terhadap perkembangan anak usia 4-24 bulan di Wilayah Kerja Puskesmas Cinunuk Kabupaten Bandung. Jurnal Stikes Bhakti Kencana. 